\title{
A Review \\ Cultural, economic and educational, status of Gujjar and Bakarwal tribal of Jammu and Kashmir
}

Correspondence to :

\section{Manju Dwivedi}

National College of

Education, Purkhoo Camp,

Jammu (J\& K) India

\section{Paper History :}

Received : 16.11.2017;

Accepted : 20.02.2018
ABSTRACT : Gujjar and Bakarwal are the third largest ethnic group in Jammu and Kashmir constitute more than 11.9 per cent of the total population of the state (Census, 2011); scheduled tribe is the only community in the state which maintain its culture and heritage throughout the ages. Various studies and reports indicate that socio-economic and educational status of Gujjar and Bakarwal in Jammu and Kashmir is not at all satisfactory. In this paper an attempt was made to examine the socio-economic and educational life of tribal in general and Gujjar and Bakarwal in particular. This paper has been reviewed on the bases of secondary data received from population census of India 2001 and 2011, journals, articles, books and reports etc. Results exhibited that literacy rate among the Gujjars was 31.65 per cent and Bakarwals was 22.51 per cent with a total 55.52 per cent of the General population of the state as per 2001 census.

KeY Words : Tribe, Gujjar, Bakarwal, Culture, Education, Economy

How To Cite This PAper : Dwivedi, Manju (2018). Cultural, economic and educational, status of Gujjar and Bakarwal tribal of Jammu and Kashmir. Internat. Res. J. Agric. Eco. \& Stat., 9 (1) : 208-214, DOI : 10.15740/ HAS/IRJAES/9.1/208-214. 